\title{
DON FRANCISCO DE LA CUEVA Y SILVA Y LOS ORÍGENES DEL TEATRO NACIONAL
}

La figura de Cueva y Silva ha sido muy deficientemente apreciada por la crítica moderna. De Serrano y Sanz arranca un juicio despectivo sobre la personalidad de nuestro autor: "Don Francisco de la Gueva y Silva, personaje estrafalario, poeta, aficionado a la astrología, por la cual se vió procesado, y autor de innumerables alegatos jurídicos consagrados a defender desde la Inmaculada Concepción hasta el pleito más insostenible..." I Esta apreciación negativa de Cueva y Silva como jurisconsulto no puede estar, como luego veremos, más lejos de la exactitud; y lo infundamentado de ella salta a la vista ya que tal juicio se basa de un lado en un incomprensible menosprecio de la defensa de la Inmaculada Concepción hecha por Gueva y Silva, y de otro en una afirmación, enteramente gratuita, de que defendía hasta el más insostenible pleito. Pero este injusto e injustificado desprecio fué recogido por Rodríguez Marín, que, sin otro apoyo, dice de Cueva y Silva que la grave Astrea "le tenía sorbido el seso en cien enredosos y enredadores alegatos forenses" 2. Por otro lado, La Barrera difundió erróneamente como fecha de la muerte de Cueva y Silva la de finales de I62 I. A esta fecha falsa (corregida por Crawford $^{3}$ ) añade La Barrera: "atribuyóse a veneno su muerte y se creyó hallar conexión entre este suceso - a la verdad bien poco extraño, dado que Cueva ya llegaba a los 70 años- y la enemistad que parece se había granjeado del Conde-Duque de Olivares" ". Nada sé de esta sospecha, que Marañón juzga imputación calumniosa ${ }^{5}$.

La personalidad literaria de Cueva y Silva no ha sido más afortunada en los juicios que sobre ella se han hecho: salvo La Barrera ${ }^{6}$, que reunió los elogios tributados a nuestro autor por sus contemporáneos y dió noticia de la existencia de un manuscrito de su tragedia Narciso, nadie se ha

Apuntes para una bibliografía de escritoras españolas, I, Madrid, Igo3, pág. 30I.

2 Francisco Rodríguez Marín, Pedro de Espinosa. Estudio biográfico, Madrid, I907, pág. I74.

3 J. P. Wickersham Grawford, en su ed. de la Trajedia de Narciso de don Francisco de la Cueva y Silva, Philadelphia, igog.

4 Catálogo del teatro antiguo español, pág. i 20.

5 El Conde-Duque de Olivares, Madrid, 1936, pág. 147.

6 Catálogo, págs. I I9-I2I. 
ocupado de Cueva y Silva sino Wickersham Crawford ${ }^{7}$, que editó esta tragedia; conjuntamente publicó varias obras líricas de nuestro poeta, pero el juicio que, en vista de la tragedia, pudo formar Crawford sobre la importancia de Cueva y Silva como autor dramático, no fué muy halagüeño.

Don Francisco de la Cueva y Silva, hijo de Jerónimo López de Medina y de la Cueva, y de doña Leonor de Silva, de ilustre familia consanguínea de los duques de Alburquerque, nació en Medina del Campo, probablemente en el primer decenio de la segunda mitad del siglo xvi. Debió estudiar en Salamanca, en donde tenemos noticias suyas en $1578^{8}$ y $5^{8} 80^{9}$. Cervantes, al alabarle en el Canto de Calíope (Galatea, publ. I $5^{85}$ ), le sitúa entre los poetas de las orillas del Tormes ${ }^{10}$. Probablemente, una vez licenciado, antes de $1586^{\mathrm{II}}$, se trasladó a Valladolid, donde en I 587 era letrado de la Chancillería ${ }^{12}$. Por los años de 1596 y 99 interviene en ciertos pleitos de Aragón, entre ellos el de la célebre causa de la baronía de Quinto ${ }^{13}$, aunque sabemos que en ${ }^{1} 59^{8}$ se hallaba en Madrid $^{14}$. Ninguna noticia tenemos de nuestro autor durante los años en que la corte estuvo en Valladolid, pero en I 606, año en que ésta vuelve a Madrid, hallamos a Cueva y Silva en la Real Villa, envuelto en un proceso sensacional.

La guerra de escrituras entre Roma y Venecia, desencadenada por la excomunión y el entredicho lanzados por Paulo V sobre el Senado y la República Veneciana, inundó a toda Europa de tratados, opúsculos y libelos en favor de uno u otro de los contendientes. Esta guerra de escrituras alcanzó, naturalmente, a España, donde los venecianos publicaron y derramaron por diversas partes papeles en favor de su pretensión, y el embajador de la República consiguió que don Francisco de la Cueva escribiese en su defensa. La Inquisición publicó entonces un edicto prohibiendo la lectura y tenencia de los papeles difundidos por los venecianos, y a nuestro autor "le prendieron por el Santo Oficio y secuestraron los papeles y bienes, y por el Consejo de Estado, por justos

7 En su citada edición de la tragedia Narciso.

8 Con motivo de las fiestas que hizo en Salamanca "el muy ilustre Sr. Nieto Megía por la nueva elección del Presidente del Consejo Real", Cueva y Silva escribe unas poesías que se publican en ese año de 1578 .

${ }^{9}$ La traducción de las Metamorfosis de Antonio Pérez Sigler que se publica en Salamanca, 1580 , lleva al frente dos sonetos laudatorios de Cueva y Silva.

${ }^{10}$ Galatea, lib. VI, fol. 334 v $^{\circ}$, ed. facsimilar de la Real Academia, I917.

11 Un soneto de don Francisco de la Cueva va al frente del Luzero de la Tierra Sancta de Pedro de Escobar, publicado en Valladolid, 1587, con privilegio y dedicatoria de 1586 .

12 En el manuscrito de la Farsa del obispo don Gonzalo, de 1587, Cueva y Silva lleva el título de "letrado" en la Chancillería de Valladolid.

13 Juan M. SÁnchez, Bibliografía aragonesa del siglo xvi.

14 Proceso por palabras injuriosas (PÉrez PAstoR, Bibliografía madrileña, Madrid, igo6, vol. III, pág. 366). 
respetos, le mandaron estar en su posada el día siguiente; pero habrá sido escarmiento para él y los demás, y no dejará de darle alguna pena" ${ }^{15}$.

El encargo del embajador de Venecia y las consideraciones que para con él tuvo la Inquisición demuestran que Cueva y Silva era ya, en este año de 1606 , un notable jurisconsulto y persona de respeto en la corte de Felipe IV; y, efectivamente, hacia estas fechas comienza a ser elogiado por escritores contemporáneos. Lope de Vega, en la enumeración de "famosos hombres de nuestros sighos" que constituye la loa del Hijo pró$\operatorname{digo}^{16}$, anterior a $\mathrm{I} 604$, incluye a don Francisco de la Cueva como personaje en quien "hallaron su esfera y luz las leyes y las musas"; es el único jurisconsulto que Lope cita. Algunos años después, su doble personalidad de jurista y de poeta es ensalzada por Cristóbal de Mesa ( $L a$ Restauración de España, lib. X, I607); y más tarde Cervantes (Viaje del Parnaso, I $\left.6 \mathrm{I}_{4}\right)^{\mathrm{I}}$, además de elogiarle como poeta, le considera "en la jurisprudencia único y raro". Don Francisco y su hermano don Antonio se citan en la Plaza universal de todas las ciencias ( 16 I5) ${ }^{18}$, de Suárez de Figueroa, entre los "valientes causídicos" de que goza España; y Herrera Maldonado le llama "Fénix de ambos derechos" (Sannazaro español, I620 $)^{19}$. Lope, a partir de esta fecha, multiplica sus alabanzas a Cueva en las dedicatorias de las comedias la Arcadia ( 1620$)^{20}$ y la Malcasada ( $162 \mathrm{I})^{21}$, en la epístola primera de la Filomena ( I62 I $)^{22}$, en la Pobreza estimada ( 1623$)^{23}$, y, muerto ya nuestro autor, en el Laurel de Apolo ( 1629$)^{24}$ y la Vega del Parnaso ( 1637$)^{25}$. Finalmente, Vicente Espinel, en el prólogo del Marcos de Obregón, dice: "¿qué autores antiguos excedieron a los que ha engendrado España en los pocos años que ha estado libre de guerras? ¿Qué oradores fueron mayores que don Fernando Carrillo, don Francisco de la Cueva, el licenciado Berrío y otros, que, con excelente estilo y levantados conceptos, persuaden a la verdad de sus partes? De no leer autores muertos, ni advertir en los vivos los secretos que llevan encerrados en lo que profesan, nace no darles el aplauso que merecen" ${ }^{26}$.

Aparte de estos elogios, con posterioridad a la prisión por el Santo Oficio en 1606 , que no fué tenida en cuenta por los críticos, tenemos una noticia a la que, en cambio, dieron excesiva importancia Serrano y Sanz

15 Cabrera de Córdoba, Relaciones de 1599 a I6I4, pág. 29 I.

16 Obras de Lope de Vega, ed. Acad., I892, vol. II, pág. $57 a$.

17 Madrid, 1614, fol. 14, ed. facsímil de la Academia, I9 I 7.

18 Madrid, 16I5, fol. 57 .

19 Pérez Pastor, op. cit., vol. II, pág. 549.

20 Obras, ed. Acad., vol. V, pág. 708.

21 Obras, ed. Acad. N., 1930, vol. XII, pág. 5 I5.

22 Obras sueltas, vol. I, pág. 410.

${ }^{23}$ Décima octava parte de las comedias de Lope de Vega, I623, pág. I8.

24 Obras sueltas, vol. I, pág. 63 , silva 11 .

25 Parte II; cf. Obras sueltas, vol. X, pág. 39.

${ }^{26}$ Marcos de Obregón, Bibl. Aut. Esp., vol. XVIII, pág. 378. 
y Rodríguez Marín, formulando de resultas su aventurado juicio acerca de nuestro autor: se trata de un proceso en que se vió envuelto en i 609 Cueva y Silva, acusado de hechicerías ${ }^{27}$.

Como abogado que era de las Cofradías de Representantes y Autores de Comedias, defendió Cueva y Silva, en i6 I i, el derecho nato de dichas cofradías a elegir el Mayordomo, Contador y Comisario de Comedias, y elevó al Consejo Supremo un pedimento que, al decir de Pellicerr ${ }^{28}$, era "claro, conciso y convincente, bien diverso de los que suelen formar algunos causídicos, sucesores suyos, difusos, desaliñados, y no menos provistos de verbosidad que de cierta eloquencia lucrosa"; en este pedimento se solicitaba fuese revocada la elección que había hecho el Protector de los Hospitales y aprobado el Consejo de Castilla.

El año I6 77 Cueva y Silva interviene en un pleito, alegando a favor de la Duquesa de Sesa ${ }^{29}$, y, cuatro años más tarde, en defensa del Duque de Osuna, con ocasión del famoso proceso que se le siguió por su actuación en Italia ${ }^{30}$. Entre los años i62 I y 23 , ejerce de censor, aprobando un libro de Pantoja de Ayala y otro de Alfonso Ramírez de Pra$\mathrm{do}^{3 \mathrm{~T}}$. La víspera de la fiesta que los abogados hacían en la iglesia de San Felipe de Madrid, el i 4 de agosto del año i624, Cueva y Silva disertó desde el púlpito en defensa de la Inmaculada Concepción ${ }^{32}$, y al año siguiente publicó su Información de derecho divino y humano por la purísima Concepción (Madrid, I625). En I 626 don Francisco es nombrado albacea por su hermano don Antonio, también ilustre jurisconsulto, fiscal de Indias y del Consejo del rey Felipe IV, con motivo de la institución del mayorazgo en favor del hijo de éste, don Baltasar Gerónimo ${ }^{33}$. La noticia de la muerte de don Francisco de la Cueva y Silva, ocurrida a comienzos de i628, es comunicada por Lope de Vega, en carta del i 4 de febrero, al desterrado Duque de Sesa, entre otras novedades de la corte: "Faltó don Francisco de la Cueva así a las letras y a los Consejos, insigne varón por cierto y digno de toda memoria . . ." 34

Capítulo aparte en la biografía de Cueva y Silva merece su amistad con Lope. Para esclarecer la personalidad de nuestro autor hemos recurrido repetidas veces, y aun lo volveremos a hacer varias más, a noticias que de él nos da Lope en sus escritos: es que Lope cita a Cueva y Silva, elogiosamente, nada menos que en nueve ocasiones, repartidas en otras

27 PÉrez PAstor, ob. cit., vol. II, pág. 405.

${ }^{28}$ C. Pellicer, Tratado histórico ... de la comedia y el histrionismo en Espa$\tilde{n} a$, I 804 , pág. 93 .

${ }^{29}$ En un pleito con los herederos del Condestable de Castilla, Madrid, I6r7; cf. Pérez Pastor, ob. eit., vol. II, pág. $4{ }^{\circ} 4$.

${ }^{30}$ ID., vol. III, pág. Io.

31 IBID., vol. III, págs. 293 y 166.

32 IвID., vol. II, pág. 405.

33 IBID., vol. II, pág. 308 .

34 Amezúa, Epistolario de Lope de Vega, Madrid, r943, vol. IV, pág. Iog. 
tantas obras ${ }^{35}$. Tal insistencia en el elogio indica por sí sola que Lope debía tener un verdadero aprecio por la persona de don Francisco; y así fué: Lope le dirige en i62 I la epístola primera de la Filomena, y, tras honrarle con los títulos y comparaciones más hiperbólicos, se reconoce su discípulo y hace constar el amor que le debe ${ }^{36}$. En el mismo año le dedica la Malcasada, y en el prólogo, después de encarecer las dotes del insigne jurisconsulto, declara " $\mathrm{el} \mathrm{amor} \mathrm{inmenso} \mathrm{que} \mathrm{le} \mathrm{tengo,} \mathrm{respeto} \mathrm{con}$ que le trato y veneración con que le miro" "37. Tal debió ser, efectivamente, el sentimiento que les unió: más que el de la amistad, el de veneración por parte de Lope hacia el ya anciano jurisconsulto, tan lleno de prestigio.

Algunos años después, cuando don Francisco publica su defensa de la Inmaculada Concepción ( 1625 ), Lope le dirige un soneto ${ }^{38}$, luego incluido en la Vega del Parnaso ( 1637$)^{39}$, en el que dice:

Quando informastes, la sentencia distes:

ya no defiendan, sino sólo alaben,

los que a la Virgen siempre libre adoran;

porque después que vos la defendistes

no les quedó defensa a los que saben

ni ocasión de dudar a los que ignoran.

En I628, en la carta donde informa al Duque de Sesa de la muerte de Cueva y Silva, añade Lope: "Lea V. Exa este soneto, que me le han agradecido, aunque a tanto varón se devían mayores elogios; pero yo ofrecí esta memoria al templo de nuestra amistad, pagando con ella alguna pequeña parte del amor que le devía: ¡O ylustre don Francisco, siempre clara luz de las letras!" ${ }^{40}$ Estas palabras, no dictadas ya por ninguna adulación, sino por sentimiento de añoranza hacia el amigo desparecido, muestran la sinceridad de los elogios que antes le tributó. Con unos versos llenos de sentido afecto le recuerda aún en el Laurel de Apolo, un año después ${ }^{4 \mathrm{I}}$ :

Llorad, pues, juntas, de su muerte ciertas, musas y leyes, si no sois las muertas;

y yo también por los que obligan tanto

de la eterna amistad vínculo santo,

diciendo a su divino entendimiento

con triste musa en lamentable acento...

35 Epístola primera de la Filomena, loa del Hijo pródigo, dedicatoria de la Malcasada, Pobreza estimada, Comedia Arcadia, Dorotea, Vega del Parnaso, Laurel de Apolo y carta al Duque de Sesa.

36 Obras sueltas, vol. I, pág. $4^{\mathrm{IO}}$.

37 Obras, Acad. N., vol. XII, 1930, pág. $5^{15}$.

${ }^{38}$ Obras sueltas, vol. X, pág. 39.

39 Parte II; Obras sueltas, vol. X, pág. 39.

40 Amezúa, ibid.

41 Obras sueltas, vol. I, pág. 63, silva $\amalg$. 
Como poeta lírico fué Cueva y Silva repetidamente alabado por sus contemporáneos: elogiosamente le citan Cervantes $^{42}$, Cristóbal de Me$\mathrm{sa}^{43}$, Lope $^{44}$ :

Oh vos, claro Francisco, a quien pretenden

las musas por su Apolo y su divino

Orfeo, en cuya música se encienden.

Vos que quitastes de la frente a Dino

el primero laurel: nestóreos años

viva ese ingenio, a cuya luz me inclino ${ }^{45}$.

Y, después de su muerte, Quevedo ${ }^{46}$ y Gracián ${ }^{47}$. Las poesías que de él conservamos no son muchas: en dos manuscritos de la Biblioteca Nacional de Madrid ${ }^{48}$ se halla el soneto "Porcia después que del famoso Bruto ; supo y creyó la miserable suerte", basado en un epigrama de Marcial (lib. I, núm. 4). Fué muy citado y alabado en el siglo xvn: se incluyó en la Primera parte de las Flores de poetas ilustres de Espinosa ( I605) ${ }^{49}$ y en la Floresta de varia poesía $a^{50}$; lo recuerda Lope en el Laurel de Apolo y dice que el soneto de Cueva es obra de juventud:

¡Qué triste de su pluma nos advierte, si bien en verde edad primero fruto:

Porcia después que del famoso Bruto supo y creyó la miserable suerte! ${ }^{5 \mathrm{I}}$

Gracián lo copia íntegro en Agudeza y arte de ingenio como modelo de expresión conceptuosa ${ }^{52}$.

Además de este soneto, se conservan una serie de composiciones muy variadas en tres manuscritos de la Biblioteca Nacional. Las contenidas en dos de ellos ${ }^{53}$ las publica Crawford ${ }^{54}$; las de un tercero están inéditas, pero son de escasa importancia, ya que se trata solamente de una cuarti-

${ }^{42}$ Canto a Caliope (Galatea, ${ }^{8} 8_{5}$, lib. VI, fol. $334 \mathrm{v}^{\circ}$; ed. facs. Acad.) y Viaje del Parnaso (1614, fol. 14; ed. facs. Acad., 1917).

43 Restauración de España, I607, lib. X.

${ }_{44}$ Dorotea, acto IV, esc. If; Epístola primera de la Filomena, I62 I (Obras sueltas, vol. I, pág. 410), y El laurel de Apolo, silva III (ibid., vol. X, pág. 39).

45 Epístola primera de la Filomena.

46 Parnaso español, i668, Melpómene xvi; Madrid, I668, pág. 108.

47 Agudeza y arte de ingenio; cf. Obras, vol. II, Madrid, 1664, pág. 15.

48 Ms. 4127, Libro de Romances nuebos con su tabla echo en el anno 1592, pág. I $7 \mathrm{I}$; y en el ms. 2244, fol. $79 \mathrm{v}^{\circ}$, que contiene noticias diversas de los años 1640 , I673, I686, I 687 y 1693 .

${ }^{49}$ Puede leerse en Bibl. Aut. Esp., vol. XLII, pág. 503 a.

50 Edición de 1896 , pág. 125.

51 Obras sueltas, vol. I, pág. 63, silva inI.

52 Madrid, I664, pág. I5.

53 Ms. 3700 , fols. $7 \mathrm{~V}^{\circ}, 8-8 b$ y 1 I I, y ms. 4127 , págs. I68-187.

54 Cf. su ed. de la Trajedia Narciso, apéndice. 
lia ${ }^{55}$ y un epitafio ${ }^{56}$. Quedan aún otros sonetos de menor interés: dos de ellos, escritos con motivo de las fiestas que hizo en Salamanca el muy ilustre señor Nieto Megía por la nueva elección de Presidente del Consejo Real (impresos en ${ }_{1578}$ ), juntamente con una canción ${ }^{57}$. Otros tres, en elogio de dos libros: la traducción de las Metamorfosis por Pérez Sigler (Salamanca, I580) y el Luzero de la Tierra Sancta de Pedro de Escobar Cabeza de Vaca (Valladolid, I587) ${ }^{58}$. Por último, al frente de su Información en derecho divino y humano va un soneto dirigido a la reina Isabel de Borbón.

Leyendo las pocas poesías de alguna importancia que de él se conservan, creo poder afirmar que no fueron inmerecidos los elogios que le tributaron sus contemporáneos.

En la polémica entre culteranos y llanos, Cueva y Silva censuró a los primeros, según Lope nos da noticia en el prólogo de la Pobreza estimada ( 1622 ), dirigido a don Francisco de Borja, virrey del Perú: "Alguna defensa se ha hecho a esa fiera introducción de voces... El doctísimo fray Ångel Medina, el señor doctor Gregorio López Madera, del consejo de Su Magestad, y don Francisco de la Cueva, jurisconsulto insigne, nos han dado su patrocinio, ya por escrito, ya con viva voz y autoridad irrefragable" 59 .

Agustín de Rojas, en su Viaje entretenido, cita a Cueva y Silva entre los que cultivaron el teatro después de Lope de Rueda, y le señala como autor de $E l$ bello Adonis ${ }^{60}$. No tenemos ninguna otra noticia de esta obra, pero conocemos en cambio su tragedia Narciso, conservada en un manuscrito autógrafo de la Biblioteca Nacional de $\mathrm{Madrid}^{6 \mathrm{I}}$ y publicada por Crawford. El que desconozcamos el Bello Adonis citado por Rojas no sería de chocar, pero bien pudiera ser que tal obra no hubiese sido escrita nunca, y que se debiese a una confusión de Rojas entre el bello Adonis y el no menos bello Narciso. De todos modos, el caudal dramático de Cueva y Silva debió ser algo abundante, ya que Lope, en la Dorotea, cuenta que "don Francisco de la Cueva y Berrío... escribieron comedias que se representaron con general aplauso" 62 .

Rojas sitúa a Cueva y Silva en la misma etapa de la historia del teatro en que escribían Berrío, Juan de la Cueva y el Cervantes de los Tratos de Argel. A esta época pertenece, efectivamente, la tragedia Narciso, así por su asunto clásico como por sus cuatro actos y la elevada pro-

55 Ms. 3985 , fol. I I $9 \mathrm{v}^{0}$.

56 Ibid., fol. 153 .

57 Bartolomé José Gallardo, Ensayo de una biblioteca española de libros raros y curiosos, vol. II, núm. I66I.

58 Ibid., vol. III, núm. 3465, y vol. II, núm. 2 I I8.

59 Décima octava parte de las Comedias de Lope de Vega, I623, pág. I8.

60 Viaje entretenido, ed. Manuel Cañete, igor, lib. I.

61 Ms. I470I; en el catálogo de Paz y Melia, núm. 2880.

62 Acto IV, esc. I. 
porción de metros largos, un 36\%. Pero la otra obra que de Cueva y Silva conozco, la inédita Farsa del obispo don Gonzalo ${ }^{63}$, es muy distinta. No corresponde ya a la época en que Rojas incluye a nuestro autor, ni siquiera a la siguiente, en que ya "se hacían tres jornadas y representaban hembras", sino a la que el mismo Rojas describe así:

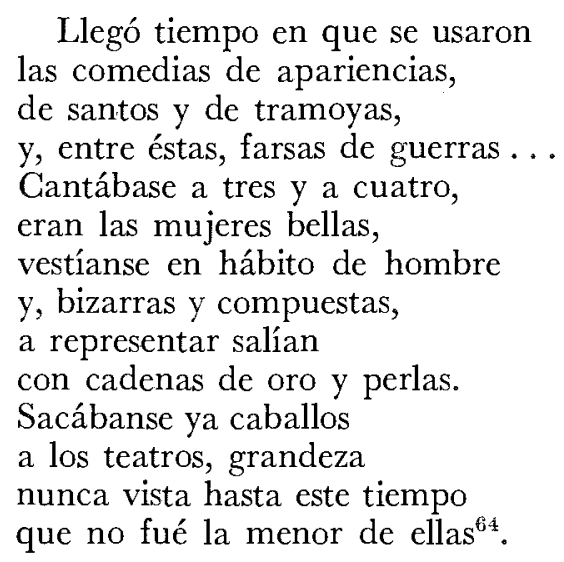

Todas aquellas notas que incluye Rojas como características de la época, y que pueden apreciarse en la simple lectura de una obra dramática, se dan en la de Cueva y Silva: es una farsa, a la vez de guerras y de santos, donde la acción se reparte en tres jornadas (frente a las cuatro de la tragedia Narciso), se recurre a menudo a efectos de tramoya y, cada dos por tres, se hace a las mujeres disfrazarse de hombres. La Farsa (cuyo manuscrito es de I $5^{87}$ ) pertenece por tanto a la época que precede inmediatamente a la de Lope y, como veremos, se encuentra a la vanguardia en la evolución del teatro.

Toda la trama de la Farsa se basa en la leyenda del cautiverio y martirio, en Granada, del obispo de Jaén don Gonzalo, que circulaba con mucha insistencia hacia I 570 entre los moriscos y cristianos viejos de Granada y Jaén ${ }^{65}$. Esta leyenda popular, junto con dos romances tradicionales, el que comienza "Ya se salen de Jaén / cuatrocientos hijosdalgo" "ee, donde se refiere la prisión del obispo, y el que dice "Reduán, bien

63 Desde que en r 908 Menéndez Pidal encontró en la Biblioteca Nacional de Madrid el manuscrito de la Farsa del obispo don Gonzalo de Francisco de la Cueva y Silva, repetidas veces ha anunciado la pronta publicación de la obra, sin que haya aún tenido lugar. Recientemente me encargó de tal labor y espero sea publicada muy en breve, junto con otras comedias del romancero, bajo la dirección de María Goyri de Menéndez Pidal.

64 Rojas Villandrando, Viaje entretenido, lib. I; ed. de Manuel Cañete, Igor, págs. I 45 y sig.

65 Menéndez Pmal, Poesía popular y romancero, en RFE, II, IgI5, págs. I05 y sigs.

66 Romancero de Durán, núms. I047-49 (vol. II, págs. 84 b - 85 b). Cf. Menendez Pidal, ibid. 
se te acuerda / que me diste la palabra" ${ }^{67}$, que parece referirse al mismo suceso visto desde el campo moro, fueron las fuentes principales de la obra. Otro romance, el de "Caballeros de Moclín, / peones de Colomera" ${ }^{68}$, explica toda una escena; y en otra se aprovecha un cuentecillo popular que venía incluyéndose en florestas y colecciones de cuentos, el mismo que años más tarde volvería a ser utilizado, una vez más en el teatro, por Tirso de Molina ${ }^{69}$.

Todas las fuentes de inspiración, como acabamos de ver, son enteramente nacionales y de raíz popular. Cueva y Silva se nos muestra aquí, por tanto, como precursor de Lope al volver los ojos hacia la tradición popular, que luego será fuente de inspiración inagotable para el Fénix de los Ingenios.

La Farsa del obispo don Gonzalo, como hemos dicho, se desarrolla en tres actos. Hay absoluto predominio de los metros cortos (un 92\%), especialmente las redondillas, y son muy escasas las octavas, que en las obras del lustro anterior abundaban tanto. Esto se debe a la agilidad de la nueva comedia. Una proporción semejante ${ }^{70}$ será la que Lope mantendrá después; antes, durante sus años mozos, el mismo Lope había empleado muy abundantemente las octavas y otros metros largos en Los hechos de Garcilaso (un $43 \%$ ).

Lope empieza a usar el romance como metro dramático por los mismos años en que se escribe la $F$ arsa, pero no es posible determinar con seguridad si alguna de estas obras de Lope es anterior o no a 1587 , fecha del manuscrito de la Farsa: según la cronología establecida por Morley y Bruerton $^{71}$, no aparece este metro en ninguna de las obras de Lope anteriores a I588. En tal caso sería don Francisco de la Cueva y Silva el primero que empleó el romance como metro dramático.

De todos modos, aun cuando alguna de las comedias de Lope donde se usa el romance fuese anterior a 1587 , la figura de Cueva y Silva seguiría teniendo una importancia excepcional como innovador de la versificación teatral, pues, a más de ser el primero o uno de los primeros en aceptar el metro romance en el teatro ${ }^{72}$, sería, sí, a todas luces, el primero que incorporó a la trama de una obra dramática romances tradicionales

67 Durán, núm. I046 (vol. II, pág. 84).

68 Ibid., núm. 1075 (vol. II, pág. 95 b).

${ }^{69}$ En la Farsa, vv. I594-I60o, don Diego se extraña del gran parecido que un pajecillo tiene con su hermano, y pregunta a éste: " $i$ Sabes si estuvo tu madre / en Córdova?--Aqueso no, / lo que sabré dezir yo / es que fué allá my padre".

${ }_{70}$ La Farsa abusa enormemente de las redondillas, que alcanzan casi el $88 \%$. En las obras posteriores de Lope, las quintillas, que en la Farsa no se emplean, reemplazan en gran parte a las redondillas; pero, en conjunto, la proporción de metros cortos y largos sigue siendo la misma.

${ }^{71}$ The chronology of Lope de Vega's comedias.

72 Además hay que tener en cuenta que la Farsa puede muy bien ser anterior a la fecha del manuscrito en que se conserva. 
completos, sin diluirlos en redondillas como hasta entonces venían haciendo Juan de la Cueva, el anónimo autor de la Segunda parte de los Hechos del Cid y el mismo Lope en Los hechos de Garcilaso ${ }^{73}$. Don Francisco de la Gueva incluye en su Farsa versos nada menos que de cinco romances, tomados evidentemente de la tradición oral: "Reduán, obispo don Gonzalo", "Caballeros de Moclín" (éste en dos escenas distintas), "Abenámar" "74 y "Morir vos queredes padre" "75. Y si en tres ocasiones los envuelve en redondillas, como habían hecho sus predecesores, en otras tres los traslada íntegramente.

Debemos observar que el metro romance es usado por Cueva y Silva sólo en tres tiradas de versos (9 I3-95o; I I63-I 2 I 2 ; I 40 I-I 452), y en los tres casos se apoya en algún romance tradicional ("Reduán", "Obispo don Gonzalo", "Caballeros de Moclin"), volviendo a las redondillas en cuanto cesa la inspiración de ellos. Este hecho nos indica que el metro romance fué introducido en el teatro a causa de la incorporación a obras dramáticas de los romances tradicionales; antes se venían cantando fuera del texto de la comedia, o a lo más, se incluía alguno de los versos en las redondillas; $y$, naturalmente, a estos romances tradicionales se sumaron versos monorrimos no tradicionales, para lograr su mejor adaptación al asunto de la obra. Por tanto, me inclino a pesar que la Farsa del obispo don Gonzalo es anterior, por ejemplo, al Verdadero amante de Lope, en que se usa el metro romance sin apoyo tradicional, y que la obra de Gueva y Silva es, entre las que hoy conocemos, la primera que emplea el metro romance.

Notable novedad, y más dado el argumento heroico y el desenlace trágico de la obra, es la existencia del elemento cómico en la Farsa. Pero además, y esto es lo más importante, los rasgos cómicos que varios personajes de la obra presentan son propios del gracioso $^{76}$ y no del bobo de las obras de Encina, Torres Naharro y Lope de Rueda: notas características del gracioso, como antihéroe que acompaña a los personajes nobles, contrastando con ellos en su modo de pensar y actuar, se dan en Zaide, acompañante del rey de Granada, en Zoraide y Guachara, compañeros de Reduán, y en Gil, soldado que aparece al lado de los hidalgos de Jaén.

Así, Zaide da consejos al rey en desprecio del honor, evidenciando su bajeza moral; comenta socarronamente la facilidad de las mujeres, y remolonea en dar una mala noticia estando con grandes ganas de desem-

${ }^{73}$ En los Hechos de Mudarra, a pesar de que la obra se inspira en el romancero, no aparece ningún verso de metro romance.

${ }^{74}$ Durán, núm. I038 (vol. II, pág. 80).

75 Durán, núm. 763 (vol. I, pág. 498). Para un estudio del romance cf. MENÉndez Pidal, en RFE, II, I9I5, págs. I y sigs.

${ }^{76}$ Para los caracteres propios del gracioso, cf. José F. Montesinos, Algunas observaciones sobre la figura del donaire en el teatro de Lope de Vega, en HMP, I, págs. 469 y sigs. 
buchar todo lo que sabe. Zoraide y Guachara hacen el amor groseramente a una criada mientras Reduán está con su dama, y salvan a éste de una apurada situación gracias a su inteligencia práctica, sin recurrir por cierto a acciones valerosas. Además, Zoraide, en la batalla con los cristianos, da muestras de cobardía, se queja de un golpe que ha recibido y, por último, recurre a un ardid traicionero para prender al obispo don Gonzalo. Gil parodia con una fregona la escena de despedida entre los hidalgos de Jaén, que parten a la batalla, y sus damas.

Es evidente, por tanto, que no existe propiamente aún en esta Farsa una figura del donaire, perfilada y única, acompañando al protagonista : son varios, como hemos visto, los personajes que se reparten tal papel y, además, en otros momentos, estos mismos personajes actúan de un modo más noble. Pero es indudable que en la Farsa se busca, quizás por vez primera, el efecto realista que resulta del contraste entre la concepción que de la vida tiene el héroe, entre su visión del amor y del honor, y la opuesta, propia del gracioso, caracterizada por la bajeza moral y el espíritu práctico. Y esta contraposición es la que luego establecerá definitivamente Lope.

En suma, don Francisco de la Cueva y Silva, jurisconsulto insigne, está injustamente excluido de las historias de la literatura española: muchos otros autores tratados prolijamente en ellas carecen de una producción como la de Cueva y Silva, que mereció los mayores encomios de los principales ingenios del siglo xvir. Además, juzgándole por las obras que hoy se conservan, vemos que, como poeta lírico, se muestra ligero y fácil en los metros cortos (cuartetas, romances) y maestro en los sonetos (fué, como sonetista, modelo reconocido); como dramaturgo, si dejamos a un lado las de los grandes autores, pocas obras tendrán la importancia de la Farsa del obispo don Gonzalo, que tan bien esclarece aquel momento crucial para nuestro teatro en que se están fraguando los pilares sobre los cuales Lope de Vega, con ímpetu genial, construirá muy pronto todo el edificio del teatro clásico español.

Madrid.

Diego Catalán Menéndez-Pidal 